\title{
Rates and predictors of switching to tenofovir alafenamide-containing ART in a nationwide cohort
}

\author{
Bernard Surial ${ }^{1}$, Matthias Cavassini ${ }^{2}$, Alexandra Calmy ${ }^{3}$, Jan Fehr ${ }^{4,5}$, Marcel Stöckle 6 , Enos Bernasconi ${ }^{7}$, Bianca Roth ${ }^{8}$, \\ Christoph A. Fux ${ }^{9}$, Helen Kovari ${ }^{4}$, Hansjakob Furrer ${ }^{1}$, Andri Rauch ${ }^{1}$, Gilles Wandeler ${ }^{1,10^{*}}$ and the Swiss HIV Cohort \\ Study
}

\begin{abstract}
Background: Tenofovir alafenamide (TAF)-containing combinations were introduced in Switzerland after October 2016 and are recommended over tenofovir disoproxil fumarate (TDF) in patients with osteoporosis or impaired renal function.

Methods: We included all participants of the Swiss HIV Cohort Study on TDF-containing antiretroviral therapy with follow-up visits after January 2016. We determined the proportion of switches from TDF to TAF overall, and among patients with risk factors for TDF toxicity, including osteoporosis, impaired renal function or marked proteinuria. We used multivariable logistic regression to explore predictors of switching from TDF to TAF.

Results: We included 5'012 patients, of whom 652 (13.0\%) had risk factors for TDF toxicity. A switch from TDF to TAF was undertaken in 2'796 (55.8\%) individuals overall, and in 465 (71.3\%) with risk factors. Predictors of switching to TAF were male sex (adjusted odds ratio 1.27, 95\% confidence interval 1.07-1.50), age > 50 years (1.43, 1.23-1.66) and the presence of risk factors for TDF toxicity $(2.21,1.77-2.75)$. In contrast, patients with a non-nucleoside reverse transcriptase inhibitor (NNRTI)-based single-pill regimen $(0.11,0.09-0.13)$, those treated in non-tertiary care centers $(0.56,0.46-0.70)$, as well as those with CD4 cell counts below 500/ $\mathrm{LL}(0.77,0.66-0.90)$ and with chronic hepatitis $C$ infection $(0.66,0.54-0.80)$ were most likely to stay on TDF.
\end{abstract}

Conclusions: Over 50\% of patients on TDF-containing therapy, including the majority of patients at risk for TDF toxicity, were switched to TAF within two years of its introduction in Switzerland. Individuals on NNRTI-based single-pill regimens were most likely to remain on TDF.

Keywords: Tenofovir alafenamide, Tenofovir disoproxil fumarate, Antiretroviral therapy, Switch, Toxicity

\section{Background}

As AIDS-related mortality is decreasing worldwide, improving the quality of life and preventing long-term side effects of antiretroviral agents have become priorities in the management of HIV infection. When treated with antiretroviral therapy (ART), the average life expectancy of HIV-infected individuals is similar to that of uninfected individuals $[1,2]$. However, life-long ART exposes

\footnotetext{
* Correspondence: gilles.wandeler@insel.ch

${ }^{1}$ Department of Infectious Diseases, Bern University Hospital, University of Bern, Bern, Switzerland

${ }^{10}$ Institute of Social and Preventive Medicine, University of Bern, Bern, Switzerland

Full list of author information is available at the end of the article
}

persons living with HIV to treatment-associated toxicity and potential drug-drug interactions (DDI) with other medications, especially in an ageing population experiencing an increasing number of non-communicable comorbidities [3]. Therefore, the modification of ART to regimens with minimal long-term toxicity and DDI is generally encouraged.

Tenofovir disoproxil fumarate (TDF) is a highly potent drug included in many first-line ART regimens recommended in the past decade [4]. However, its use is associated with bone mineral disorders and proximal renal tubulopathy, which can lead to impaired renal function [5-8]. Tenofovir alafenamide (TAF), a newer tenofovir

(c) The Author(s). 2019 Open Access This article is distributed under the terms of the Creative Commons Attribution 4.0 International License (http://creativecommons.org/licenses/by/4.0/), which permits unrestricted use, distribution, and 
prodrug, reaches high intracellular levels while exposing patients to low plasma levels, an important driver of tenofovir-related toxicity. TAF has the same antiviral activity but a better renal and bone safety profile than TDF: In registration trials, patients who switched from TDF to TAF experienced an increase in bone mineral density and a decrease in proteinuria and renal tubular markers $[9,10]$. Despite the lack of long-term safety and efficacy data on the use of TAF outside of randomized controlled trials, the International Antiviral SocietyUSA (IAS-USA) advises against the use of TDF in patients at risk of kidney or bone disease [11]. In addition, the European AIDS Clinical Society (EACS) defines the following risk groups for which TAF should be preferred to TDF in order to prevent long-term toxicity: (a) established or high risk of chronic kidney disease; (b) concomitant use of nephrotoxic drugs, and (c) osteoporosis/ osteopenia, related risk factors or a history of fragility fractures [12].

In Switzerland, TAF became available in combination with emtricitabine/elvitegravir/cobicistat (F/TAF/EVG/c, Genvoya ${ }^{\circ}$ ) in October 2016, with emtricitabine alone (F/ TAF, Descovy ${ }^{\circ}$ in May 2017, and with emtricitabine/rilpivirine (F/TAF/RPV, Odefsey ${ }^{\circ}$ ) in July 2018. These drugs were introduced at a slightly lower price than their TDF-containing counterparts, and no generic version of TDF-containing compounds other than TDF as a single substance are available to date in Switzerland. We used data from the nationwide Swiss HIV Cohort Study (SHCS) to determine the proportion of patients with and without risk factors for TDF-related toxicity who had been switched from TDF to TAF and explored individual predictors for being switched.

\section{Methods}

\section{Swiss HIV cohort study}

The SHCS (www.shcs.ch) is a prospective cohort that enrolls close to $80 \%$ of all HIV-infected adults living in Switzerland [13]. Demographic, HIV-specific (e.g. date of diagnosis, most probable mode of transmission) and laboratory data (e.g. plasma viral load, CD4 cell counts, and lipid levels) are recorded at enrollment, and every 6 months thereafter. Clinical events (e.g. myocardial infarction, fragility fractures) are regularly reported using dedicated forms, and a detailed history of ART and comedications is available for all participants. Local ethical committees of all cohort centers approved this cohort study and all patients provided written informed consent.

\section{Study population, definitions and outcomes}

We included all HIV-infected adults with one or more clinical follow-up visits after January 1st 2016 and who were on a TDF-containing regimen for more than 30 days. Patients were classified as having switched if TAF was introduced within 90 days after stopping TDF, and if TAF was continued for at least 14 days. To restrict our analysis to direct switches from TDF to TAF, we excluded patients who were prescribed abacavir during the time between the use of TDF and TAF. The decision to switch or not was at the discretion of the treating physician, and no additional guidance was given. Database closure was on the 1st of August 2018.

Our primary aim was to describe the proportion of patients having switched from TDF to TAF and to identify related predictors. Additionally, the same outcomes were explored in patients "at risk of TDF toxicity", defined as the presence of at least one of the following risk factors: [1] estimated glomerular filtration rate (eGFR) $<60 \mathrm{~mL} / \mathrm{min}$, [2] marked proteinuria (protein-to-creatinine ratio $\geq$ $50 \mathrm{mg} / \mathrm{mmol}$ [ $\geq 500 \mathrm{mg} / \mathrm{g}]$ ) or [3] osteoporosis (Tscore $\leq-2.5$ in any bone mineral density measurement and/or occurrence of fragility fractures). Our secondary aims were to explore the reasons for discontinuing TDF, as reported by treating physicians, using pre-defined stopping reasons which are systematically recorded through an online tool. Finally, we determined whether TAF was used together with drugs that are categorized as "do not co-administer" for TAF but not TDF according to the Liverpool Drug Interaction Group Database [14], in order to evaluate potential problematic DDI with TAF.

Arterial hypertension was defined as at least two measurements $>140 \mathrm{mmHg}$ systolic or $>90 \mathrm{mmHg}$ diastolic and/or currently being on antihypertensive treatment, diabetes mellitus as HbA1c $\geq 6.5 \%$ and/or currently being on antidiabetic treatment and dyslipidemia as total-cholesterol to HDL ratio $>5$ and/or currently being on lipid lowering treatment. Chronic hepatitis B virus (HBV) infection was defined by the presence of a positive hepatitis $\mathrm{B}$ surface antigen, and hepatitis $\mathrm{C}$ infection (HCV) as a detectable $\mathrm{HCV}$ viral load at any time-point, irrespective of $\mathrm{HCV}$ treatment. A history of cardiovascular disease included the previous occurrence of any of the following: myocardial infarction, ischemic stroke, arterial interventions including coronary angioplasty/stenting, coronary artery by-pass grafting and venous thromboembolism.

\section{Statistical analyses}

We compared baseline demographic and clinical characteristics, comorbidities and laboratory values between patients "at risk of TDF toxicity" and those without risk factors using Chi-square, Wilcoxon rank sum and ttests, where appropriate. Baseline was defined as [1] switching date for patients on TAF, [2] October 1st 2016 for patients remaining on TDF, or [3] registration date for patients remaining on TDF who joined the SHCS after October 1st 2016. Multivariable logistic regression was used to explore risk factors of switching to TAF, 
and included the following explanatory variables: sex, age $(<50$ or $\geq 50$ years), region of origin, education status, CD4 cell count $(<500$ or $\geq 500 / \mu \mathrm{L})$, follow-up in a tertiary versus non-tertiary center (including private physicians), comorbidities (chronic $\mathrm{HBV}$ or $\mathrm{HCV}$ infections, history of cardiovascular disease, diabetes, arterial hypertension and dyslipidemia), the presence of at least one risk factor for TDF associated toxicity, and use of boosted protease inhibitors (PI) or nonnucleoside reverse transcriptase inhibitor (NNRTI)based single-pill regimens. Osteoporosis was excluded from the multivariable analyses because bone mineral density measurements were only available in one third of patients. However, we repeated the main analyses in patients with at least one risk factor for TDF toxicity, including osteoporosis and eGFR. Odds ratios from multivariable analyses are presented in Forest plots, stratified by the presence or absence of any risk factors for TDF toxicity. All statistical analyses were performed using Stata 15.1 (Stata Corp, College Station, TX, USA).

\section{Results}

\section{Study population}

Of 10'246 HIV-infected individuals in active follow-up after January 1st 2016, 8'245 (80.5\%) ever received TDF for more than 30 days. After excluding patients who switched to abacavir or initiated TAF more than 90 days after stopping TDF ( $\left.n=3^{\prime} 233\right), 5^{\prime} 012$ patients remained in our study population. Overall, 3'645 (72.7\%) participants were male, 789 (15.7\%) were of African origin, and the median age was 49 years (interquartile range [IQR] 41-56). Measurements of creatinine and proteinuria at baseline were available for 4' 813 (96.0\%) and 3'102 (61.9\%) patients respectively, and a bone densitometry measurement was available in 1'624 (32.4\%) individuals. In total, 652 patients $(13.0 \%)$ had one or more risk factors for TDF-associated toxicity: 243 had an eGFR $<60 \mathrm{~mL} / \mathrm{min}$ (4.8\%), 154 (3.1\%) had marked proteinuria, and osteoporosis was diagnosed in 325 (6.5\%) patients. Table 1 summarizes the main demographic and clinical characteristics of the study population, stratified by the presence of at least one risk factor for developing TDFrelated toxicity. Patients with risk factors were older, less likely to be of African origin, but more likely to be persons who inject drugs (PWID) and to have arterial hypertension, dyslipidemia, diabetes or a history of cardiovascular disease.

\section{Rates and predictors of switching from TDF to TAF}

Nearly two years after the introduction of TAF in Switzerland, 2'796 (55.8\%) individuals had TDF replaced by TAF, with large differences across cohort centers, ranging from 32.6 to $65.3 \%(p<0.001)$. Overall, most individuals received F/TAF and a third drug $\left(n=1{ }^{\prime} 635\right.$, $58.5 \%)$, followed by F/TAF/EVG/c ( $\left.\mathrm{n}=1^{\prime} 116,39.9 \%\right)$ and $\mathrm{F} / \mathrm{TAF} / \mathrm{RPV}(n=45,1.6 \%)$. In those who received $\mathrm{F} /$ TAF, the most common third drug was dolutegravir (661, 40.4\%), followed by boosted darunavir (277, $16.9 \%)$, nevirapine $(243,14.9 \%)$ and raltegravir $(130,8 \%)$. In 1475 (52.8\%) instances, the switch from TDF to TAF was the only modification in the ART regimen with all other components remaining unchanged.

Of the 652 patients with at least one risk factor for TDF-associated toxicity, 465 (71.3\%) were switched to TAF. Patients switched at a median of 9.7 months (IQR 7.1-12.2 months) after the introduction of TAF into the Swiss market, without a significant difference between those with or without TDF-toxicity risk factors (9.5 versus. 9.7 months, $p=0.15$ ). Thirty-four patients had access to TAF prior to its official licensing, either through an early access program or within a study protocol, and remained in our study population.

In multivariable analyses, patients were more likely to switch to TAF if they were male, older than 50 years, had at least one risk factor for TDF toxicity, or arterial hypertension. In contrast, patients with CD4 cell counts below $500 / \mu \mathrm{L}$, those followed in non-tertiary centers, and $\mathrm{HCV}$-coinfected individuals were more likely to remain on TDF. An important predictor for staying on TDF was the use of NNRTI-based single-pill regimens (Table 2), with comparable estimates for efavirenz and rilpivirine based single-tablet regimens. Compared to the population without risk factors, the proportion of individuals who switched to TAF was higher in the presence of an eGFR $<60 \mathrm{~mL} / \mathrm{min}(77.4 \%)$, osteoporosis $(71.4 \%)$, or marked proteinuria $(64.9 \%$, Fig. 1). In patients with an eGFR $<60 \mathrm{~mL} / \mathrm{min}$ who remained on TDF, median eGFR at baseline was $56.5 \mathrm{~mL} / \mathrm{min}$ (IQR $52.6-58.0 \mathrm{~mL} / \mathrm{min}$ ) and none had an eGFR $\leq 30 \mathrm{~mL} / \mathrm{min}$.

In analyses restricted to patients with TDF-related risk factors, the associations between switching to TAF and renal impairment, the use of NNRTI-based single-pill regimens and co-infection with $\mathrm{HCV}$ remained statistically significant. In contrast, higher age, male sex or the presence of arterial hypertension were not associated with switching to TAF among persons with TDF-related risk factors. (Fig. 2a and b). The most common ART regimens in patients staying on TDF despite TDF-related risk factors were fixeddose combinations of F/TDF/RPV (31.6\%) and F/ TDF/efavirenz (25.1\%).

\section{Reasons for switching from TDF to TAF and presence of drug-drug interactions}

The main reasons for replacing TDF by TAF, as reported by SHCS physicians, were "prevention of expected sideeffects" (24.9\%), followed by "simplification of current 
Table 1 Characteristics of the study population at baseline ${ }^{a}$

\begin{tabular}{|c|c|c|c|}
\hline Characteristics & $\begin{array}{l}\text { No TDF-toxicity risk } \\
N=4^{\prime} 360\end{array}$ & $\begin{array}{l}\text { TDF-toxicity risk } \\
N=652\end{array}$ & $P$ \\
\hline Male sex (\%) & $3194(73.3)$ & $451(69.2)$ & 0.03 \\
\hline Median age in years (IQR) & $48(40-54)$ & $56(50-62)$ & $<0.001$ \\
\hline African origin (\%) & $742(17.0)$ & $47(7.2)$ & $<0.001$ \\
\hline High-level education (\%) & $1471(33.7)$ & $181(27.8)$ & 0.01 \\
\hline Transmission group (\%) & & & $<0.001$ \\
\hline MSM & $2071(48.7)$ & $270(42.4)$ & \\
\hline PWID & $396(9.3)$ & $108(17.0)$ & \\
\hline other & $1789(42.0)$ & $259(40.7)$ & \\
\hline Median CD4 count in cells/uL (IQR) & $640(486-828)$ & $615(443-826)$ & 0.01 \\
\hline Median CD4 nadir in cells/uL (IQR) & $226(122-334)$ & $171(75-273)$ & $<0.001$ \\
\hline Type of center (\%) & & & 0.44 \\
\hline Tertiary care center & $2256(51.7)$ & $348(53.4)$ & \\
\hline Other & $2104(48.3)$ & $304(46.6)$ & \\
\hline Chronic HBV infection (\%) & $291(7.1)$ & $47(7.5)$ & 0.71 \\
\hline Chronic HCV infection (\%) & $509(11.9)$ & $115(18.0)$ & $<0.001$ \\
\hline History of CV disease (\%) & $293(6.7)$ & $95(14.6)$ & $<0.001$ \\
\hline Diabetes (\%) & $245(5.6)$ & $77(11.8)$ & $<0.001$ \\
\hline Arterial hypertension (\%) & $2264(51.9)$ & $405(62.1)$ & $<0.001$ \\
\hline Dyslipidemia (\%) & 1'864 (42.8) & $345(52.9)$ & $<0.001$ \\
\hline Median eGFR in mL/min (IQR) & $93.8(80.6-106.3)$ & $73.0(56.3-95.5)$ & $<0.001$ \\
\hline eGFR category (\%) & & & $<0.001$ \\
\hline$>90 \mathrm{~mL} / \mathrm{min}$ & $2390(57.3)$ & $198(30.9)$ & \\
\hline $60-90 \mathrm{~mL} / \mathrm{min}$ & $1782(42.7)$ & $200(31.2)$ & \\
\hline$<60 \mathrm{~mL} / \mathrm{min}$ & 0 & $243(37.9)$ & \\
\hline Proteinuria (\%) $[n=3102]$ & & & $<0.001$ \\
\hline$<15 \mathrm{mg} / \mathrm{mmol}$ & $1920(72.5)$ & $139(30.6)$ & \\
\hline $15-50 \mathrm{mg} / \mathrm{mmol}$ & $727(27.5)$ & $162(35.6)$ & \\
\hline$>50 \mathrm{mg} / \mathrm{mmol}$ & 0 & $154(33.9)$ & \\
\hline Osteoporosis (\%) & & & n.a. \\
\hline T-score $\leq-2.5[n=1624]$ & 0 & $273(41.9)$ & \\
\hline Fragility fracture & 0 & $77(11.8)$ & \\
\hline Combined & 0 & $325(49.9)$ & \\
\hline Pl-based ART (\%) & $994(22.8)$ & $184(28.2)$ & 0.01 \\
\hline NNRTI-based single-pill regimen (\%) & $1755(40.3)$ & $223(34.2)$ & 0.01 \\
\hline
\end{tabular}

TDF Tenofovir disoproxil fumarate, IQR Interquartile range, MSM Men having sex with men, PWID Persons who inject drugs, HBV Hepatitis B virus, HCV Hepatitis $C$ virus, CV Cardiovascular, eGFR Estimated glomerular filtration rate, PI Protease inhibitor, ART Antiretroviral treatment, NNRTI Non-nucleoside reverse transcriptase inhibitor

${ }^{a}$ time of switch for those who switched, or 1st October 2016 (introduction of TAF in Switzerland) or registration date if registered after that date for those who did not switch

TDF toxicity risk defined as presence of a least one of the following risk factors: eGFR $<60 \mathrm{~mL} / \mathrm{min}$, urine protein-to-creatinine ratio of $\geq 50 \mathrm{mg} / \mathrm{mmol}$ or osteoporosis

treatment" (9.2\%), and "presence of established kidney toxicity" (8.2\%) (Table 3). Less specific reasons such as patient's wish and physician's decision were given in $1^{\prime} 372$ cases (49.1\%). The use of drugs which are contraindicated with TAF was rare in our cohort:
Three individuals switched to TAF (all once-daily) while taking rifabutin, and one patient switched while taking carbamazepine. Within the group of patients that remained on TDF, treatment with rifampicin $(n=12)$, rifabutin $(n=14)$ and carbamazepine $(n=3)$ 
Table 2 Predictors of switching from TDF to TAF

\begin{tabular}{|c|c|c|c|c|}
\hline \multirow[b]{2}{*}{ Variable } & \multirow[b]{2}{*}{$N(\%)$} & \multirow[b]{2}{*}{ Switched (\%) } & \multicolumn{2}{|l|}{ Multivariable Analysis } \\
\hline & & & $\begin{array}{l}\text { Adjusted odds ratio } \\
(95 \% \mathrm{Cl})\end{array}$ & $P$ \\
\hline Male sex & 3'645 (72.7) & $2^{\prime} 102(57.7)$ & $1.27(1.07-1.50)$ & 0.01 \\
\hline Age $>50$ years & 2'235 (44.6) & $1^{\prime} 413(63.2)$ & $1.43(1.23-1.66)$ & $<0.001$ \\
\hline African origin & $789(15.7)$ & $377(47.8)$ & $0.83(0.67-1.01)$ & 0.07 \\
\hline High level education & $1 ' 652(33.0)$ & $923(55.9)$ & $1.16(1.00-1.35)$ & 0.05 \\
\hline CD4 $<500 / \mu \mathrm{L}$ at baseline ${ }^{a}$ & 1'406 (28.1) & $754(53.6)$ & $0.77(0.66-0.90)$ & $<0.001$ \\
\hline Follow-up in a non-tertiary care center & 2'408 (48.0) & 1'169 (48.6) & $0.56(0.46-0.70)$ & $<0.001$ \\
\hline \multicolumn{5}{|l|}{ Comorbidities } \\
\hline Chronic HBV infection & $338(6.7)$ & $188(55.6)$ & $0.97(0.74-1.26)$ & 0.81 \\
\hline Chronic HCV infection & $624(12.5)$ & $349(55.9)$ & $0.66(0.54-0.80)$ & $<0.001$ \\
\hline Diabetes & $322(6.4)$ & $202(62.7)$ & $0.95(0.71-1.26)$ & 0.70 \\
\hline Arterial hypertension & 2'669 (53.3) & $1 ' 584(59.4)$ & $1.21(1.04-1.40)$ & 0.01 \\
\hline History of CV disease & $388(7.7)$ & $243(62.6)$ & $0.79(0.61-1.03)$ & 0.08 \\
\hline Dyslipidemia & 2'209 (44.1) & $1 ' 336(60.5)$ & $1.09(0.94-1.26)$ & 0.26 \\
\hline At least one risk factor for TDF toxicity ${ }^{b}$ & $652(13.0)$ & $465(71.3)$ & $2.21(1.77-2.75)$ & $<0.001$ \\
\hline PI-based ART & 1'178 (23.5) & $855(72.6)$ & $0.97(0.81-1.16)$ & 0.74 \\
\hline NNRTI-based single-pill regimen & $1 ' 978$ (39.5) & $522(26.4)$ & $0.11(0.09-0.13)$ & $<0.001$ \\
\hline
\end{tabular}

TDF Tenofovir disoproxil fumarate, TAF Tenofovir alafenamide, HBV Hepatitis B virus, HCV Hepatitis C virus, CV Cardiovascular, PI Protease inhibitor, ART Antiretroviral treatment, NNRTI Non-nucleoside reverse transcriptase inhibitor

atime of switch for those who switched, or 1st October 2016 (introduction of TAF in Switzerland) or registration date if registered after that date for those who did not switch

bosteoporosis, impaired renal function or marked proteinuria

were more common. No patient in the study population received phenytoin.

\section{Discussion}

Two years after the introduction of TAF in Switzerland, $56 \%$ of all patients on TDF-containing ART overall, and $72 \%$ of those with risk factors for TDF-associated toxicity had TDF replaced by TAF. The highest proportions of patients switched to TAF were found in men, those older than 50 years, as well as in individuals with renal impairment, whereas the use of a NNRTI-based singlepill regimen was predictive of staying on TDF. The main reason for switching to TAF, as reported by treating physicians, was the prevention of potential side effects due to TDF. Our study underlines the importance of monitoring treatment changes and related predictors in

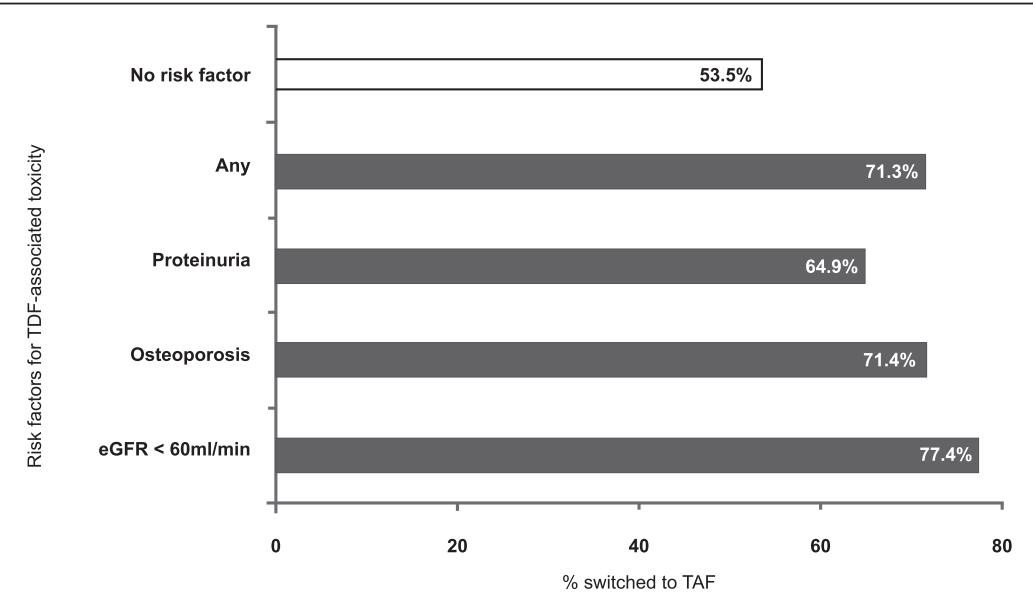

Fig. 1 Rates of switching from TDF to TAF, according to risk factor. eGFR Estimated glomerular filtration rate, TDF Tenofovir disoproxil fumarate, TAF Tenofovir alafenamide. Proteinuria defined as urine protein-to-creatinine ratio $>50 \mathrm{mg} / \mathrm{mmol}$ 


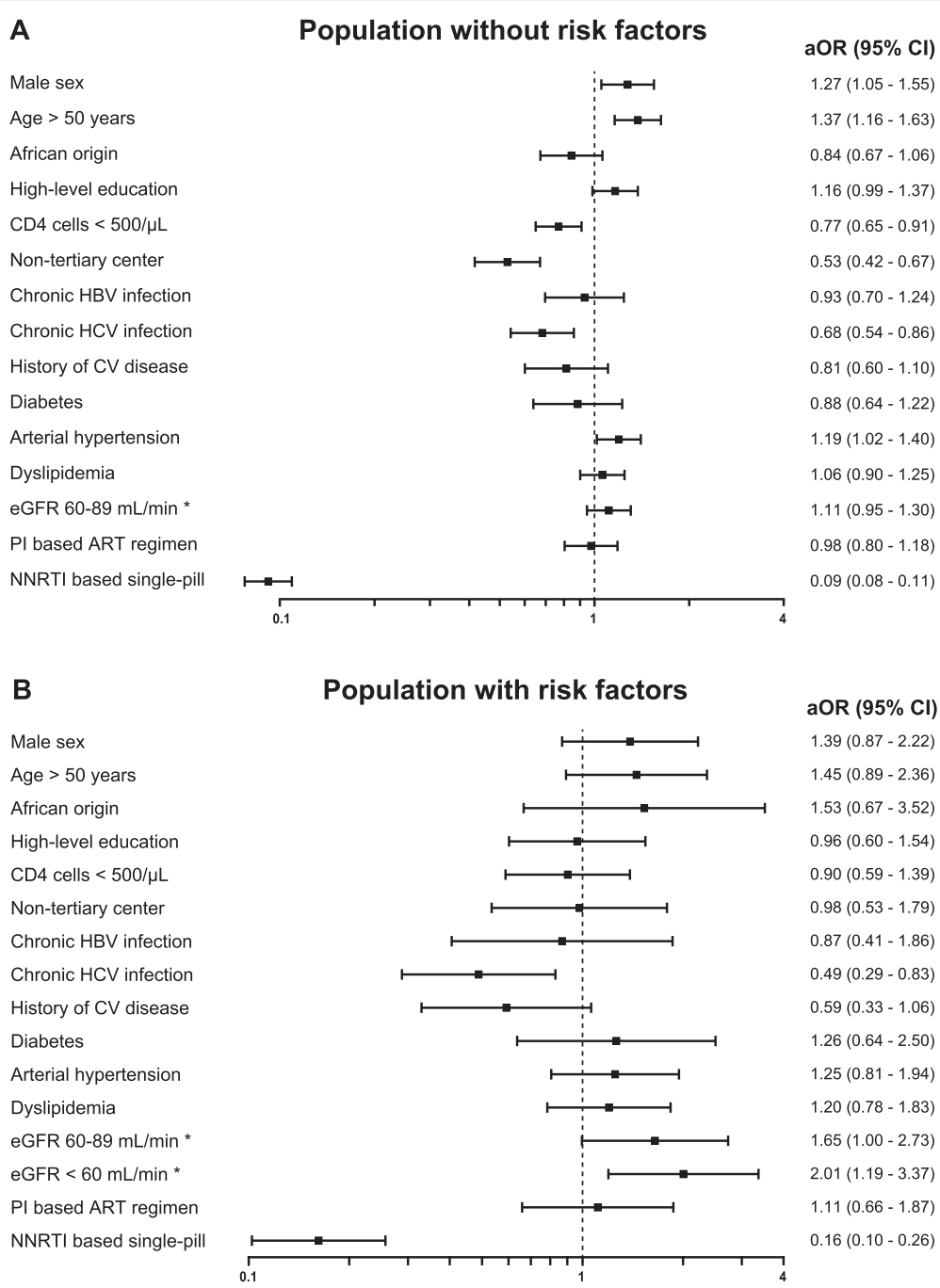

* Reference: eGFR $\geq 90 \mathrm{~mL} / \mathrm{min}$

Fig. 2 Probability of switching from TDF to TAF. Adjusted odds ratios (aOR) and 95\% confidence intervals (CI) in study population without (Panel a) and with risk factors for TDF-associated toxicity (Panel b). aOR Adjusted odds ratio, HBV Hepatitis B virus, HCV Hepatitis C virus, CV

Cardiovascular disease, eGFR Estimated glomerular filtration rate, PI Protease inhibitor, ART Antiretroviral treatment, NNRTI Non-nucleoside reverse transcriptase inhibitor

order to evaluate a program's potential to react to changes in guidelines and new drug availability, as well as to foster patient-centered management.

Although the majority of individuals on TDFcontaining ART were switched to TAF, we found large differences in the use of TAF across treatment sites and between tertiary and non-tertiary sites. Similar diversity in patterns of treatment changes were observed across other studies: in a cohort of 444 patients on TDFcontaining ART in Germany, only 34\% of all patients switched to TAF-containing ART within 2 years of its introduction [15]. In contrast, a retrospective analysis of four treatment centers in the US showed that of all switches performed within the first year after TAF became available, $86 \%$ received TAF as the new drug [16].
The lower cost of F/TAF compared to F/TDF in countries without generic F/TDF could partly explain these results: for instance, generic F/TDF was available in Germany but not in the US and Switzerland. Furthermore, some physicians may have decided to wait for the availability of generic F/TDF instead of switching individuals without risk factors for TDF-toxicity to TAF. Eventually, these generic compounds never made it to the market in Switzerland due to legal issues.

Our study highlights the multitude of factors which potentially play a role in shaping physicians' choices and patient preferences in terms of ART modalities. Although only $8.2 \%$ of all switches in our study could be attributed to the presence of established kidney dysfunction, as reported by treating physicians, a low eGFR 
Table 3 Reasons for switching from TDF to TAF

\begin{tabular}{llll}
\hline TDF stopping reason & $\begin{array}{l}\text { No TDF-toxicity risk } \\
\left(n=2^{\prime} 331\right)\end{array}$ & $\begin{array}{l}\text { TDF-toxicity risk } \\
(n=465)\end{array}$ & $\begin{array}{l}\text { Total } \\
\left(n=2^{\prime} 796\right)\end{array}$ \\
\hline Prevention of expected side-effects & $614(26.3 \%)$ & $83(17.9 \%)$ & $697(24.9 \%)$ \\
Established kidney toxicity & $147(6.3 \%)$ & $83(17.9 \%)$ & $230(8.2 \%)$ \\
Toxicity, other & $124(5.3 \%)$ & $34(7.3 \%)$ & $158(5.7 \%)$ \\
Treatment simplification & $223(9.6 \%)$ & $34(7.3 \%)$ & $257(9.2 \%)$ \\
Drug-drug interaction & $15(0.6 \%)$ & $3(0.7 \%)$ & $18(0.6 \%)$ \\
Patient's wish & $195(8.4 \%)$ & $48(10.3 \%)$ & $243(8.7 \%)$ \\
Physician's decision & $375(16.1 \%)$ & $88(18.9 \%)$ & $463(16.6 \%)$ \\
Other reason, not specified & $581(24.9 \%)$ & $85(18.3 \%)$ & $666(23.8 \%)$ \\
Missing & $57(2.5 \%)$ & $7(1.5 \%)$ & $64(2.3 \%)$ \\
\hline
\end{tabular}

TDF Tenofovir disoproxil fumarate, TAF Tenofovir alafenamide.

TDF toxicity risk defined as presence of a least one of the following risk factors: eGFR $<60 \mathrm{~mL} / \mathrm{min}$, urine protein-to-creatinine ratio of $\geq 50 \mathrm{mg} / \mathrm{mmol}$ or osteoporosis

(especially below $60 \mathrm{~mL} / \mathrm{min}$ ) was a predictor for receiving TAF. This finding is in line with previous reports [16-18] and such a strategy is supported by the results of randomized controlled trials in patients with renal impairment $[10,19]$. The presence of boosted PIbased regimens was not associated with an increase in switching to TAF in our study, even though these patients are at increased risk of TDF-associated toxicity. In a randomized controlled trial, Goicoechea et al. showed a faster decline in renal function when TDF was co-administered with boosted PI, possibly due to increased tenofovir plasma levels [20]. Similarly, a meta-analysis of randomized trials only favored TAF over TDF for renal outcomes when a booster was co-administered [21]. The single most important predictor of staying on TDF was the use of NNRTI-based single-pill regimens. For these regimens, TAF-containing counterparts were either unavailable as a single-pill or introduced late during the observation period. We hypothesize that even in the presence of risk factors, patients and physicians may have preferred to keep the convenient and welltolerated single-pill regimen in order to secure adherence and virological efficacy. Many patients without risk factors for TDF-toxicity remained on TDF in our cohort, a practice supported by the EACS guidelines [12] and current data which are insufficient to recommend TAF over TDF for these patients. Since TDF is available in generic form in many countries, its use could considerably reduce HIV-related costs.

In general, the potential for DDI of TDF and TAF is similar. However, drugs such as carbamazepine, phenytoin, rifampicin or rifabutin seem to be more problematic when combined with TAF than with TDF [14]. For instance, the administration of TAF in combination with rifampicin led to significantly lower intracellular and plasma levels of tenofovir in pharmacokinetic studies
$[19,22]$. While twice-daily dosing of TAF is sufficient to overcome the decrease in plasma levels induced by rifampicin and rifabutin, carbamazepine or phenytoin seem to decrease tenofovir plasma levels to an extent that TAF can lose its therapeutic effect. Despite the nearly systematic switch to TAF in some of our study centers, only one of 2'796 patients who switched to TAF was receiving a contra-indicated co-medication (carbamazepine). Considering the very low number of inadequate drug combinations after the switch to TAF, our study shows that the event of significant DDI in the context of single-drug substitutions remains very low when HIV physicians are familiar with important DDI mechanisms.

The large number of patients analyzed during the months following the registration of TAF in Switzerland allowed us to explore the main drivers of ART changes in response to the availability of drugs with an improved toxicity profile. Furthermore, the presence of detailed information on treatment changes and stopping reasons helped us improve our understanding of the determinants of switching from TDF- to TAF-containing ART. However, although this study is representative for current treatment strategies in Switzerland, extrapolations to other health care systems should be undertaken with caution. Additionally, given the large number of potentially nephrotoxic drugs with complex toxicity profiles taken by our patients, we could not include comprehensive information on their use in our analysis. As the prescription of such drugs may have motivated physicians to recommend switching to a TAF-containing regimen, we may have failed to grasp the reason for switching in some cases. Similarly, as the assessment of bone mineral density was available in only $32 \%$ of our study population, we may have underestimated the proportion of patients at risk of TDF-toxicity. The potential under-estimation of osteoporosis in our cohort was 
mitigated by our inclusion of data on fragility fractures systematically collected within the SHCS. Since TAF is not recommended during pregnancy, the desire to have children may have influenced treatment choices in some women and led to lower switching rates among this group of patients. Finally, information about physicians' motivation to recommend a treatment change to their patients was limited to predefined stopping reasons and were inconclusive in almost $50 \%$ of cases. Such information would have been important to better understand the large differences in TAF prescriptions between tertiary centers and other health care facilities.

\section{Conclusions}

The majority of patients at risk for TDF-toxicity were switched from TDF to TAF within two years after its introduction in Switzerland. Among 30\% of patients at risk of TDF-toxicity who did not switch during this time-period, being on a NNRTI-based single-pill regimen seemed to be an important reason for remaining on TDF. However, large differences across clinics were observed and related reasons should be further explored. Since current recommendations on switching to TAF are based on limited data from selected groups of patients in randomized controlled trials, further data on clinical outcomes after the introduction of TAF in cohorts such as ours remain essential to inform optimal patient management.

\section{Abbreviations}

ART: Antiretroviral therapy; DDI: Drug-drug interaction; EACS: European AIDS Clinical Society; eGFR: Estimated glomerular filtration rate; HBV: Hepatitis B virus; HCV: Hepatitis C virus; IAS-USA: International Antiviral Society-USA; IQR: Inter-quartile range; NNRTI: Non-nucleoside reverse transcriptase inhibitor; PI: Protease inhibitors; PWID: Persons who inject drugs; SHCS: Swiss HIV Cohort Study; TAF: Tenofovir alafenamide; TDF: Tenofovir disoproxil fumarate

\section{Acknowledgments}

We thank all patients, doctors, and nurses associated with the Swiss HIV Cohort Study (SHCS). The members of the SHCS are Anagnostopoulos A, Battegay M, Bernasconi E, Böni J, Braun DL, Bucher HC, Calmy A, Cavassini M, Ciuffi A, Dollenmaier G, Egger M, Elzi L, Fehr J, Fellay J, Furrer H, Fux CA, Günthard HF (President of the SHCS), Haerry D (deputy of "Positive Council"), Hasse B, Hirsch HH, Hoffmann M, Hösli I, Huber M, Kahlert CR (Chairman of the Mother \& Child Substudy), Kaiser L, Keiser O, Klimkait T, Kouyos RD, Kovari H, Ledergerber B, Martinetti G, Martinez de Tejada B, Marzolini C, Metzner KJ, Müller N, Nicca D, Paioni P, Pantaleo G, Perreau M, Rauch A (Chairman of the Scientific Board), Rudin C, Scherrer AU (Head of Data Centre), Schmid P, Speck R, Stöckle M (Chairman of the Clinical and Laboratory Committee), Tarr P, Trkola A, Vernazza P, Wandeler G, Weber R, Yerly S.

\section{Authors' contributions}

$B S, A R$ and GW designed the study, performed statistical analyses and drafted the initial manuscript. MC, AC, JF, MS, EB, BR, CAF, HK and FH contributed to the conception of the study and revised the manuscript for substantial intellectual content. All authors read and approved the final manuscript.

\section{Funding}

This work was funded by the framework of the SHCS, supported by the Swiss National Science Foundation [SNF grant number 177499, SHCS project number 842]. GW was supported by a Professorship from the Swiss National Science Foundation [PP00P3_176944]. The funders had no role in study design, data collection and analysis, decision to publish, or preparation of the manuscript

\section{Availability of data and materials}

The datasets used and/or analyzed during the current study are available from the corresponding author on reasonable request.

\section{Ethics approval and consent to participate}

This cohort study was approved by Local ethical committees of each cohort center: "Ehtikkomission beider Basel", "Kantonale Ethikkommission Bern", "Comité d'Ethique Genève", "Comission cantonale d'éthique Vaud", "Comitato etico cantonale Ticino", "Ethik-Kommission St. Gallen", and "Kantonale EthikKommission Zürich" and all patients provided written informed consent.

\section{Consent for publication}

Not applicable.

\section{Competing interests}

BS reports support to his institution for travel grants from Gilead Sciences outside the submitted work. MC reports support to his institution for expert opinion and/or travel grant from Abbvie, Gilead, MSD and Viiv, and an unrestricted research grant from Gilead and Viiv outside the submitted work. JF reports support to his institution for advisory boards and/or travel grants from and/or unrestricted grants from Abbvie, Gilead Sciences, Janssen-Cilag, MSD, and Viiv-Healthcare. All remuneration was provided outside the submitted work. HF reports unrestricted educational grant supports to his home institution by Gilead Sciences, Viiv, Abbvie, Bristol-Myers Squibb and MSD outside the submitted work. AR reports support to his institution for advisory boards and/or travel grants from Janssen-Cilag, MSD, Gilead Sciences, Abbvie and Bristol-Myers Squibb, and an unrestricted research grant from Gilead Sciences. All remuneration went to his home institution and not to AR personally, and all remuneration was provided outside the submitted work. GW reports support to his home institution for advisory boards and/or travel grants from MSD, Gilead Sciences and Abbvie, and an unrestricted research grant from Gilead Sciences. All remuneration was provided outside the submitted work.

\section{Author details}

${ }^{1}$ Department of Infectious Diseases, Bern University Hospital, University of Bern, Bern, Switzerland. Division of Infectious Diseases, University Hospital of Lausanne, University of Lausanne, Lausanne, Switzerland. ${ }^{3}$ Division of Infectious Diseases, Geneva University Hospital, University of Geneva, Geneva, Switzerland. ${ }^{4}$ Division of Infectious Diseases and Hospital Epidemiology, University Hospital Zurich, University of Zurich, Zurich, Switzerland. ${ }^{5}$ Department of Public Health, Epidemiology, Biostatistics and Prevention Institute, University of Zurich, Zurich, Switzerland. ${ }^{6}$ Division of Infectious Diseases and Hospital Epidemiology, University Hospital Basel, University of Basel, Basel, Switzerland. ${ }^{7}$ Division of Infectious Diseases, Regional Hospital of Lugano, Lugano, Switzerland. ${ }^{8}$ Division of Infectious Diseases, Cantonal Hospital of St Gallen, St Gallen, Switzerland. 'Division of Infectious Diseases, Cantonal Hospital of Aarau, Aarau, Switzerland. ${ }^{10}$ Institute of Social and Preventive Medicine, University of Bern, Bern, Switzerland.

Received: 28 April 2019 Accepted: 10 September 2019 Published online: 10 October 2019

\section{References}

1. Gueler A, Moser A, Calmy A, Gunthard HF, Bernasconi E, Furrer H, et al. Life expectancy in HIV-positive persons in Switzerland: matched comparison with general population. AIDS. 2017;31(3):427-36.

2. Wandeler G, Johnson LF, Egger M. Trends in life expectancy of HIV-positive adults on antiretroviral therapy across the globe: comparisons with general population. Curr Opin HIV AIDS. 2016;11(5):492-500.

3. Smit M, Brinkman K, Geerlings S, Smit C, Thyagarajan K, Sighem A, et al. Future challenges for clinical care of an ageing population infected with HIV: a modelling study. Lancet Infect Dis. 2015;15(7):810-8. 
4. World Health Organization (WHO). Consolidated guidelines on the use of antiretroviral drugs for treating and preventing HIV infection. 2016.

5. Fux CA, Simcock M, Wolbers M, Bucher HC, Hirschel B, Opravil M, et al. Tenofovir use is associated with a reduction in calculated glomerular filtration rates in the Swiss HIV cohort study. Antivir Ther. 2007;12(8):1165-73.

6. Hall AM, Hendry BM, Nitsch D, Connolly JO. Tenofovir-associated kidney toxicity in HIV-infected patients: a review of the evidence. Am J Kidney Dis. 2011:57(5):773-80.

7. Bedimo R, Maalouf NM, Zhang S, Drechsler H, Tebas P. Osteoporotic fracture risk associated with cumulative exposure to tenofovir and other antiretroviral agents. AIDS. 2012;26(7):825-31.

8. McComsey GA, Kitch D, Daar ES, Tierney C, Jahed NC, Tebas P, et al. Bone mineral density and fractures in antiretroviral-naive persons randomized to receive abacavir-lamivudine or tenofovir disoproxil fumarate-emtricitabine along with efavirenz or atazanavir-ritonavir: Aids clinical trials group A5224s, a substudy of ACTG A5202. J Infect Dis. 2011;203(12):1791-801.

9. Mills A, Arribas JR, Andrade-Villanueva J, DiPerri G, Van Lunzen J, Koenig E, et al. Switching from tenofovir disoproxil fumarate to tenofovir alafenamide in antiretroviral regimens for virologically suppressed adults with HIV-1 infection: a randomised, active-controlled, multicentre, open-label, phase 3, non-inferiority study. Lancet Infect Dis. 2016;16(1):43-52.

10. Post FA, Tebas P, Clarke A, Cotte L, Short WR, Abram ME, et al. Brief report: switching to Tenofovir Alafenamide, Coformulated with Elvitegravir, Cobicistat, and Emtricitabine, in HIV-infected adults with renal impairment: 96-week results from a single-arm, multicenter, open-label phase 3 study. J Acquir Immune Defic Syndr. 2017:74(2):180-4.

11. Saag MS, Benson CA, Gandhi RT, Hoy JF, Landovitz RJ, Mugavero MJ, et al. Antiretroviral drugs for treatment and prevention of HIV infection in adults: 2018 recommendations of the international antiviral society-USA panel. JAMA. 2018:320(4):379-96.

12. European AIDS Clinical Society (EACS). Guidelines for the treatment of HIVpositive adults. October 2018. Available from: http://www.eacsociety.org/ guidelines/eacs-guidelines/eacs-guidelines.html. Accessed 13 Aug 2019.

13. Schoeni-Affolter F, Ledergerber B, Rickenbach M, Rudin C, Gunthard HF, Telenti A, et al. Cohort profile: the Swiss HIV cohort study. Int J Epidemiol. 2010;39(5):1179-89.

14. Liverpool Drug Interaction Group UoL. Prescribing resources: interactions with NRTI 2018 [Available from: https://www.hiv-druginteractions.org/. Accessed 13 Aug 2019.

15. Bickel M, Wyen C, Spinner C, Baumgarten A. Switch from tenofovir disoproxil fumarate (TDF)- to tenofovir alafenamide (TAF)-based regimens in clinical practice - real-world data of the German PROPHET cohort study: HIV Glasgow; 2018.

16. Elion R, Eron J, Santiago S, Sax P. Clinical observations of antiretroviral (ART) switching in HIV-suppressed patients after availability of TAF: HIV Glasgow; 2018.

17. Brown K, Sutherland G, O'Hara R, Bell D, editors. Real world experience using Tenofovir Alafenamide fumarate. UK. HIV Glasgow; 2018.

18. Vergori A, Lorenzini P, Cozzi-Lepri A, Maggiolo F. Incidence and determinants of antiretroviral switching away from TDF-based backbone in the recent years in the Icona Foundation cohort: HIV Glasgow; 2018.

19. Pozniak A, Arribas JR, Gathe J, Gupta SK, Post FA, Bloch M, et al. Switching to Tenofovir Alafenamide, Coformulated with Elvitegravir, Cobicistat, and Emtricitabine, in HIV-infected patients with renal impairment: 48-week results from a single-arm, multicenter, open-label phase 3 study. J Acquir Immune Defic Syndr. 2016;71(5):530-7.

20. Goicoechea M, Liu S, Best B, Sun S, Jain S, Kemper C, et al. Greater tenofovir-associated renal function decline with protease inhibitor-based versus nonnucleoside reverse-transcriptase inhibitor-based therapy. J Infect Dis. 2008;197(1):102-8.

21. Hill A, Hughes SL, Gotham D, Pozniak AL. Tenofovir alafenamide versus tenofovir disoproxil fumarate: is there a true difference in efficacy and safety? J Virus Erad. 2018;4(2):72-9.

22. Cerrone M, Alfarisi O, Neary M, Marzinke MA, Parsons TL, Owen A, et al. Rifampicin effect on intracellular and plasma pharmacokinetics of tenofovir alafenamide. J Antimicrob Chemother. 2019:dkz068.

\section{Publisher's Note}

Springer Nature remains neutral with regard to jurisdictional claims in published maps and institutional affiliations.

Ready to submit your research? Choose BMC and benefit from:

- fast, convenient online submission

- thorough peer review by experienced researchers in your field

- rapid publication on acceptance

- support for research data, including large and complex data types

- gold Open Access which fosters wider collaboration and increased citations

- maximum visibility for your research: over $100 \mathrm{M}$ website views per year

At BMC, research is always in progress.

Learn more biomedcentral.com/submissions 